\title{
Study on the Impact of Local Public Expenditure on Housing Price-An Empirical Analysis Based on Provincial Panel Data
}

\author{
Shihao Li \\ School of Economics, Jinan University, Guangzhou, China \\ Email: shlee15@foxmail.com
}

How to cite this paper: Li, S.H. (2018) Study on the Impact of Local Public Expenditure on Housing Price-An Empirical Analysis Based on Provincial Panel Data. Modern Economy, 9, 247-262. https://doi.org/10.4236/me.2018.92016

Received: January 8, 2018

Accepted: February 8, 2018

Published: February 11, 2018

Copyright $\odot 2018$ by author and Scientific Research Publishing Inc. This work is licensed under the Creative Commons Attribution International License (CC BY 4.0).

http://creativecommons.org/licenses/by/4.0/

\section{(c) (i) Open Access}

\begin{abstract}
Based on the discussion about transmission mechanism of local public expenditure on housing price under different housing market types, the paper performs an empirical study on the influence of various public expenditures on housing price by using Chinese panel data of provinces from 2007 to 2015 . According to the result, public education expenditure and public transportation expenditure have prominent capitalization effect on housing price. Among the expansions of various local public expenditures, public education expenditure is the most effective type to promote the capitalization of commercial housing. In dynamic panel test, the capitalization effect of public expenditure maintains significant after the introduction of consumer expectation, which is consistent with the regression result of static panel. At last, the paper puts forward some relevant policy suggestions for the government to optimize the structure of public expenditure, guide consumer expectations reasonably and promote the sound development of real estate market.
\end{abstract}

\section{Keywords}

Capitalization of Public Expenditure, Housing Price, Consumer Expectation

\section{Introduction}

In recent years, the sharp rise of housing price has caused widespread concern in society. The surging housing price has not been suppressed fundamentally, though strict regulatory policies are formulated in all regions. Because of the substantial connection between housing and residents' job and life, the reasons of housing price changes have also become the focus of scholars' attention.

With the steady development of social economy as well as the improvement of 
residents' income level, the housing preference of people is more focused on the perfection of public services around the residence. The local governments are responsible for the supply of public goods in China. In the last decade, the proportion of local fiscal expenditure in the total fiscal expenditure has increased to $85.41 \%$ in 2016 from $77 \%$ in 2007. Therefore, the support of local fiscal expenditure plays an important role in road traffic, education and medical care, as well as social security. The local governments of economically developed provinces can provide more fiscal expenditures to improve the supply of local public goods. With the urbanization and population flow, the regions featured with better supply of public goods would attract significant in-migration, and the housing price would go up as well. Against this backdrop, it is of great significance to study the influence of local public expenditure on the housing price in our country.

The economists have believed that the housing price is decided by the construction cost and the economic fundamentals that reflect the relationship between supply and demand. Yet according to the relevant researches, the housing prices changes in recent years cannot be fully explained by economic fundamentals. The status quo in China is the lack of investment channels for residents and the missing of real estate possession tax, which endows housing with great investment value. The simultaneously rising of volume and price in real estate market for many years drives up the investment sentiment greatly, thus the housing market has the characteristics of investment market. Under the assumption of investment market, the consumer expectation of house-purchase can be viewed as an important factor that affects housing price.

Therefore, through the literature review and theoretical analysis, based on the discussion about transmission mechanism of local public expenditure on housing price under different housing market types, the paper performs an empirical study on the influence of various public expenditures on housing price by using Chinese panel data of provinces from 2007 to 2015. The paper aims to explore the capitalization effect and level of public expenditure in China, and further analyze the differences of capitalization levels so as to reflect residents' preference for public goods.

The innovation of this article lies in:

1) Previous studies focused on the impact of the scale of local fiscal expenditure on housing prices, while few scholars further analyzed the differences in the impact of local public expenditure on housing prices, that is, the differences in the degree of capitalization of different public expenditures. By analyzing the differences in the degree of capitalization of different public expenditures, this paper provides the basis for measuring the efficiency and structure of public expenditures.

2) Housing has both the properties of consumer goods and the properties of investment goods. Therefore, there is no conclusion about whether the housing market is biased toward the consumer market or the investment-oriented mar- 
ket. Most scholars in China study the capitalization of public expenditure based on the framework of the consumer housing market. Fewer people analyze the extent and impact of capitalization of public expenditures under the framework of the investment housing market. In this paper, we test the dynamic and static panel model, and the empirical results show that our housing market is more investment-oriented market. For investment-oriented market framework, the transmission mechanism and impact of public expenditure capitalization are discussed.

The shortcoming of this article is that adopting inter-provincial panel data is too macroscopic, resulting in too few data observations. The data from 70 big and medium-sized cities, which are frequently announced by the state, should be adopted. The empirical results are more credible.

\section{Literature Review, Theoretical Analysis and Hypothesis Proposing}

In view of the relationship between local fiscal revenue and expenditure and housing price, foreign scholars focus on analyzing the impact of local public expenditure property tax on housing price. The earliest theoretical analysis about the impact of public service expenditure on housing price is conducted by American economist Tibbert who put forward the theory of "vote by foot" in 1956. The theory means that on the basis of population free flow, people can select the most suitable neighborhood by means of measuring the public services and tax policies in different regions. The important contribution of the theory is to point out the fact that under the full flow of population and the competition of local governments, population location may allow the government public fiscal expenditure and tax revenue to capitalize into the housing price, thus the local public goods can be allocated effectively through housing market [1].

After the investigation of 53 cities and towns around New Jersey, American economist Oates (1968) explores the relationship between public service expenditure, property tax and housing price based on Tiberian Model and draws the conclusion that the public service expenditure is positively related with housing price, while the property tax is negatively related with housing price [2]. Later Langkevin and Tianlunian (2004) et al. perform a large amount of empirical studies to explore the relationship between property taxes, public expenditure and housing prices by using data from different regions of United States, and the study results have mirrored the conclusion of Oates [3].

With the development of urbanization level as well as the improvement of local public expenditure system in China, the supply of local public goods has gradually reflected "vote by foot" mechanism. Many scholars have performed relevant empirical analysis on local public expenditure and housing price. Taking 35 large and medium-sized cities in China as the research object, Liang Ruobing and Tang Yun (2008) use the dynamic panel regression model to prove that the intensity of local fiscal expenditure and the level of local public services 
have significantly positive effect on the commercial housing prices [4]; according to the data of 31 provinces and municipalities, Du Xuejun, Huang Zhonghua and Wu Cifang (2009) use Granger causality test to verify that the growth of local public expenditure plays a significant role in the increase of housing prices [5]. The growth of housing price caused by the expansion of public expenditure is usually called the capitalization of public expenditure by academic circles. For example, Guo Xiaodong and Lu Chaoyun (2009) define the capitalization of fiscal expenditure as the phenomenon of public goods utility being transferred into the housing asset income. Deng Huihui, Yu Yihua and Gong Ming (2013) studies the relationship between public services and housing price by using spatial lag two-way fixed model and proves that the imbalance of public service level is the vital reason for regional departure of housing price.

With the in-depth study, scholars began to differentiate the types of public expenditure and explore the influence of different public goods supplies on housing price, such as traffic conditions and education level, etc. The earliest study on the influence of single public goods supply on housing price is conducted by Alonso (1964) who analyzes the impact of communicating distance of housing price by establishing "land-market" model. According to the model, the farther from the urban center, the higher the traffic costs will be, therefore, the distance between housing and urban center is inversely proportional to land price [6]. Taking metro line in Beijing as the sample, domestic scholars Feng Changchun and Li Weitai et al. (2011) explore the impact of subway on housing price within $2 \mathrm{~km}$ around the metro line. According to the research, the track traffic represented by subway has a significant impact on the surrounding housing price. The impact effect will decline exponentially with the distance increasing between housing and subway, and the impact effect will be no longer significant when the housing is $2 \mathrm{~km}$ away from the subway.

High-class educational resources are conducive to improve the housing value within the school district. By using housing price and school district model, American scholars Bayer, Ferreira and McMillan (2007) perform the research on San Francisco Bay Area and find that every 5\% of improvement in schools' teaching quality can increase $1 \%$ of residents' willingness to make house-purchase, and the associated impact is featured with consumption upgrade, which means that with the growth of income level, residents will produce higher demands for high-quality education [7]. The regional distribution of educational resources may have influence on housing price. On the basis of sample study on schools distribution in Shanghai, Feng Hao and Lu Ming (2010) find that the differential distribution of quantity and quality of educational resources in single region has been partly reflected on the differences of regional housing prices, which proves that education expenditure has a capitalization effect on housing price.

According to Tiebout theory, different groups have different preferences on public goods, thus the willingness to pay are different at various public goods [8]. Such difference will be fully reflected on the market bidding behavior of 
residents during location selection. People with same preferences tend to realize the clustering phenomenon during the constant bid-rent of location selection, and different groups will live separately to form dispersion phenomenon. The clustering and dispersion phenomenon can amplify the capitalization effect of public goods supply in housing price and form a social multiplier to strengthen the capitalization effect of public expenditure. For example, according to the study prepared by Bayer (2007), the capitalization effect of school on housing price has increased by $70 \%-75 \%$ due to the existence of social multiplier. The residential sorting can help local government provide public goods more efficiently based on the preference differences of residents. Yet Glaeser (2001) argues that the dispersion of residential areas caused by excessive residential sorting can restrain the consumption of low-income groups on public goods.

To sum up, the predecessors perform researches mainly based on two aspects: one is to study the impact of local public expenditure on housing price; second is to study the impact of single public goods supply on housing price. According to the general study on the relationship between the supply of public goods and real estate price, population can perform migration flow by comparing the supply levels of public goods, while the supply levels of public goods can be capitalized into housing price. The clustering and dispersion phenomenon caused by bid-rent of location selection can strengthen the impact of public goods supply on housing price in the form of social multiplier. Based on the empirical analysis of urban and inter-provincial data in our country, domestic scholars verify that the local public expenditure in China has a significant galvanizing impact on housing price.

The previous studies focus on the impact of local fiscal expenditure on housing price, yet few scholars have analyzed the impact differences of various local public expenditures on housing price, namely the differences of capitalization among different public expenditures. And also, the impact of consumer expectation has been less considered among all factors that affect housing price.

Combining with Tiebout model and the extended analysis of model, the theoretical framework is to analyze the selection of consumer's residential area based on the maximization of consumer utility as well as the income constraint. It contains a basic assumption that the real estate market is a consumer-type market oriented by relationship between supply and demand. Based on the assumption of consumer-type market, the theoretical logic of scholars to analyze the capitalization of public expenditure is the improvement of residents' demand. The local governments improve the public service levels via fiscal expenditures, and the rational consumers tend to migrate to meet their own demands for public goods and maximize their utility. Housing demand in areas with better public services will increase, which brings about the rising of local housing price.

The fundamental factors such as population, mortgage interest rate and resident income in China are basically stable in the short term, therefore, the residents' demands for housing shall not experience sharp fluctuation. According to 
the statistics result however, under the background of soaring housing-price-to-income ratio as well as the increasingly growth of housing price, the transaction volume of new commercial housing in 35 large and medium-sized cities of China is increased rapidly with an average annual growth rate of $14 \%$ during 2006-2013. The upstream of market participants cannot be fully explained by the relationship between supply and demand.

According to the latest China's Regional Financial Operation Report released by People's Bank of China (2017), due to the limited investment channels and the low investment return, housing also carries the investment demand of residents. If housing is acted as investment goods, the housing price will obviously be affected by market expectations. Some domestic scholars have performed relevant studies on the influencing mechanism of relationship between market participants' price expectation and housing price fluctuations. Zhou Jingkui (2005) believes that if there is asymmetric information between purchaser and real estate market, consumer beliefs and feedback effect will result in housing price fluctuations [9]. Based on the research data of Chengdu City, Zheng Siqi and Wang Yixiao (2007) find that consumers will improve their housing demands based on expectation of housing price rising in the coming year. Song Chunhe (2010) argues that the expectation of housing price rising will cause the early release of housing demand. The increasingly growth of housing price will reinforce consumers' expectation of housing price rising, which forms a continually positive feedback.

Assuming that housing market is an investment market oriented by market expectation, the mechanism that market expectation affects transaction behaviors lies in the comparison between the expected return of housing investment and that of other investment tools. If the return on housing investment is high, the expectation of housing price rising will become intense, which can promote a rapid increase of housing price. The return of housing investment mainly includes two parts: housing rental income and housing value improvement [10]. The price-to-rents ratio maintains a quite low level in China for a long term; therefore, it is uneconomical behavior to select housing investment simply by virtue of rental income. The investment return of housing is more dependent on the housing value improvement, while the housing value improvement is derived from the engergization of surrounding public services. The expansion of local public expenditure brings about the wealth effect of housing appreciation for the housing owners. And the missing of real estate possession tax results in a desirable expected return rate on investment real estate market. Therefore, the capitalization effect of public expenditure can strengthen the expectation of housing price rising under the assumption of an investment market.

Based on the above analysis, the paper puts forward the following research hypotheses:

Hypothesis 1: The capitalization effect of public expenditure is remarkable, and different public expenditures have different effects on housing price; the 
difference reflects resident's preference for public expenditure at present.

Hypothesis 2: The real estate market is more inclined to the investment market at present and greatly affected by consumer expectations. The capitalization effect of public expenditure on housing price maintains positively prominent.

Based on the panel data of 30 provinces in China during 2007-2015, the paper makes use of the static panel model to test the effect of various public expenditures on housing price and analyzes the differences on the capitalization effects of different public expenditures. Consumer expectation is introduced into the dynamic panel model so as to verify that whether the current real estate market in our country is the investment market oriented by market expectation, as well as to test that whether the impact of public expenditure on housing price is consistent with the results of static panel. Based on the results of empirical study, the paper will provide reasonable policy suggestions for local governments to adjust the proportion and structure of public expenditure and promote the sound development of real estate market.

\section{Empirical Analysis}

\subsection{Data Sources, Index Selection and Model Specification}

The paper performs empirical test and analysis based on the panel data of 30 provinces in China during 2007-2015 (Tibet and Ningxia are not included due to data missing). The model data comes from China Statistical Yearbook of Territorial Resources, China Statistical Yearbook of Real Estate, China Statistical Yearbook and China Statistical Yearbook of Employment and Population. The new reform of government fiscal revenue and expenditure took effect in 2007 and has listed various expenditures about the classification of government expenditures; therefore, the data in the paper is selected from 2007. Due to the time lag in China's fiscal data, the data range is only collected in 2015.

Based on the previous literature review and the above analysis, the paper takes the selling price of commercial housing as explained variable and the local public expenditure as explanatory variable. Public education expenditure, public transport expenditure and public health expenditure that may have significant impact on housing price are selected to test the differences on the impact of different public expenditures on housing price.

As a heterogeneous commodity, housing actually is affected by the housing quality, geographical location and economic location, etc. As for the selection of control variables, the paper introduces the following indicators as control variables from the perspective of housing's supply and demand and monetary policy:

1) Land price: the value standard is the income of unit land leasing. From the perspective of real estate developer, land price and housing price are like "flour and bread", and land price can be viewed as the prime cost of housing price. The rising of land price can bring about the growth of real estate development cost and then drive up the selling price of housing. The effect of land price on housing price is expected to be positive. 
2) Annual incremental completed residential area: the value standard is the "completed housing area" of all cities provided by China Statistical Yearbook (Million square meters). From the perspective of housing supply, the annual incremental completed residential areas can reflect the actual incremental housing supply each year. The adequate housing supply may have certain inhibiting effect on housing price; therefore, the coefficient is expected to be negative.

3) Urban population density: the value standard is population density (Person/Square kilometer) of urban built-up areas provided by China Statistical Yearbook of Employment and Population. From the perspective of housing demand, population density can better reflect the rigid demand of registered population for housing. In view of the fact that rural areas are mainly self-built houses, urban population density is selected as the measurable indicator for higher precision. In general, population density is in direct proportion to housing price, so the coefficient is expected to be positive.

4) Per capita disposable income. The per capita disposable income of every province is used to reflect the local economic level and residents' affordable ability. The coefficient is expected to be positive.

5) Loan rate for purchasing house. From the perspective of monetary policy, the medium and long-term ( 5 years and above) benchmark loan rate are used to signify the loan rate for purchasing house. Housing loan policies such as interest rate are important exogenous variable that affect the changes of housing price, and the increase of housing loan rate can significantly drive up residents' housing cost. Therefore, housing price is negatively related with interest rate, and the coefficient is expected to be negative.

In order to avoid the influence of heteroscedasticity and data fluctuations, the paper performs a natural logarithm operation to all variables so as to get new variable. Thus the following logarithmic econometric model is formulated in the paper:

$$
\ln \left(\mathrm{HP}_{\mathrm{it}}\right)=\alpha_{1} \ln \left(\mathrm{AEE}_{\mathrm{it}}\right)+\alpha_{2} \ln \left(\mathrm{ATE}_{\mathrm{it}}\right)+\alpha_{3} \ln \left(\mathrm{AME}_{\mathrm{it}}\right)+\gamma \mathrm{X}_{\mathrm{it}}+\omega_{\mathrm{t}}+\varepsilon_{\mathrm{it}}
$$

Herein $\alpha$ is a constant term; while $\alpha_{1}, \alpha_{2}$ and $\alpha_{3}$ are explanatory variable coefficients. And i refers to individual unit, $\mathrm{t}$ refers to the period. HP stands for the selling price of housing, while LP refers to the income of land releasing; AEE, ATE and AME respectively represent the per capita education expenditure, per capita transport expenditure and per capita medical expenditure. $X$ is the control variable containing per capita disposable income (PCDI), population density (PD), annual incremental completed residential area (BA) and the logarithmic value of medium and long-term loan rate (LR); $\omega$ is annual fixed effect, while $\mathcal{\varepsilon}$ represents white noise error. The definition and statistical description of all variables are shown as Table 1.

\subsection{Empirical Test Steps and Analysis}

\subsubsection{Static Panel Test on the Impact of Local Public Expenditure on Housing Price}

Static panel is used to inspect the relationship between local public expenditure 
Table 1. Variable definition and descriptive statistics.

\begin{tabular}{|c|c|c|c|c|c|c|}
\hline variables & $\begin{array}{l}\text { The meaning of } \\
\text { economic variables }\end{array}$ & $\begin{array}{l}\text { Mean } \\
\text { value }\end{array}$ & $\begin{array}{l}\text { Standard } \\
\text { deviation }\end{array}$ & Maximum & Minimum & $\begin{array}{l}\text { Expected } \\
\text { symbol }\end{array}$ \\
\hline $\mathrm{HP}$ & $\begin{array}{l}\text { Average price of commodity } \\
\text { house sales } / \mathrm{m}^{2}\end{array}$ & 5130.35 & 3382.37 & 22,300 & 1851 & + \\
\hline LP & $\begin{array}{l}\text { the income of unit } \\
\text { land leasing } / \mathrm{m}^{2}\end{array}$ & 1231.82 & 2242.22 & $26,050.37$ & 60.08 & + \\
\hline AEE & $\begin{array}{l}\text { Per capita education } \\
\text { expenditure }\end{array}$ & 1300.00 & 676.11 & 3942.27 & 348.1 & + \\
\hline ATE & $\begin{array}{l}\text { per capita transport } \\
\text { expenditure }\end{array}$ & 527.94 & 494.67 & 3508.71 & 28.83 & + \\
\hline AME & $\begin{array}{l}\text { per capita medical } \\
\text { expenditure }\end{array}$ & 530.02 & 301.45 & 1707.07 & 93.15 & + \\
\hline PCDI & per capita disposable income & $21,127.33$ & 7862.12 & 52,961 & $10,012.3$ & + \\
\hline $\mathrm{PD}$ & $\begin{array}{c}\text { population density } \\
\text { (people per square kilometer) }\end{array}$ & 2773.64 & 1240.82 & 5967 & 622 & + \\
\hline BA & $\begin{array}{l}\text { annual incremental completed } \\
\text { residential area } \\
\text { (thousand square meters) }\end{array}$ & 2885.93 & 2026.97 & $10,296.96$ & 171.2 & - \\
\hline LR & long-term loan rate (\%) & 6.52 & 0.59 & 7.34 & 5.49 & - \\
\hline
\end{tabular}

and housing price. The regression Equation (1) in Table 2 is the regression result of fixed effect on the sample data, while Equations (2) and (3) are the regression results that respectively use random effect and mixed OLS. The estimated results of three above methods are concordant based on the positive and negative regression coefficient as well as the prominence of regression coefficient, which indicates that the regression result is robust.

F-test and Hausman test are conducted to the models so as to determine which model shall be used for the regression analysis: mixed OLS model, fixed effect model or random effect model. The test results are shown as follows:

The probability of F statistical magnitude is 0.0000 . According to the test results, the fixed effect is superior to mixed OLS, while the fixed effect model is better than random effect model. Thus the paper selects the fixed effect model as the final conclusion.

According to the regression results, the model goodness of fit is 0.9314 , and the overall significance level " $\mathrm{F}$ " is 393.76 , which indicates that the regression equation has a quite good imitative effect. Among the explanatory variables, local public education expenditure and public transportation expenditure is in prominently direct proportion to housing price, and the public education expenditure has the greatest effect on housing price with the elastic coefficient of 0.14 , which means that $1 \%$ of improvement on per capita public education expenditure will cause $0.14 \%$ of increasing on housing price; the elastic coefficient of public transportation expenditure is 0.08 , which indicates that public education expenditure and public medical expenditure have prominent capitalization 
Table 2. Result of static regression.

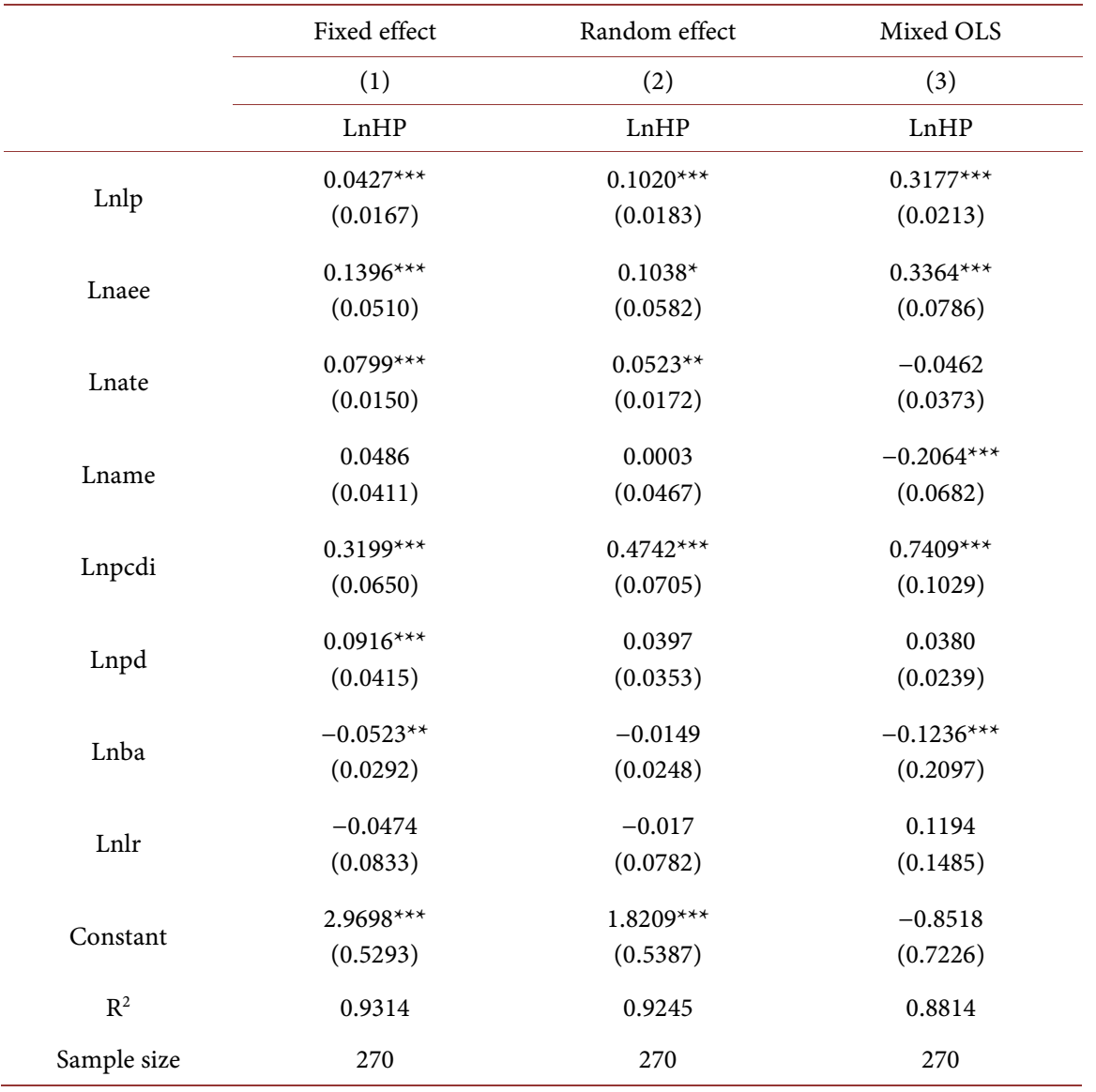

effect on housing price. Yet the impact of public medical expenditure on housing price fails to pass the significance test, which indicates that the medical expenditure in China has no capitalization effect on housing price.

As for control variables, the test results of variables such as per capita disposable income, population density and annual incremental completed residential area which reflect the relation between supply and demand are all prominent and consistent with the expectation. The impact of per capita disposable income on housing price is greater than that of other variables, the per capita disposable income therefore can be considered as the major factor that affects housing price. Yet the housing loan rate that reflects the monetary policy fails to pass the significance test, which indicates that the real estate market is the consumer market dominated by the relation between supply and demand under the static panel model, and the capitalization of public expenditure is of great prominence.

\subsubsection{Robustness Test of Introducing Consumer Expectation}

The capitalization effects of different public expenditures are tested in the static panel test, and the individual effects of regions are solved via the fixed effect. The test results are generally robust and unbiased.

Consumer expectation is introduced to the models in the dynamic panel test. If consumers have adaptive expectations on the rising of housing price, the cur- 
rent demand of housing purchasers will affected by the changes of previous housing prices. Consumers' adaptive expectations on the rising of housing price can greatly promote the current demand of housing purchase. Based on the existing research literature, the lagged growth rate of housing price is used as the proxy variable of consumer expectation.

The models can be reconfigured as follows:

$$
\begin{aligned}
\ln \left(\mathrm{HP}_{\mathrm{it}}\right)= & \alpha_{1} \ln \left(\mathrm{HP}_{\mathrm{it}-1}\right)+\alpha_{2} \ln \left(\mathrm{AEE}_{\mathrm{it}}\right)+\alpha_{3} \ln \left(\mathrm{ATE}_{\mathrm{it}}\right) \\
& +\alpha_{4} \ln \left(\mathrm{AME}_{\mathrm{it}}\right)+\gamma \mathrm{X}_{\mathrm{it}}+\omega_{\mathrm{t}}+\varepsilon_{\mathrm{it}}
\end{aligned}
$$

$\ln \left(\mathrm{HP}_{\mathrm{it}-1}\right)$ is the previous growth rate of housing price and used as the proxy variable of consumer expectation here. Other explanatory variables are the same as Equation (3.1). Because the lagged term of explained variable is introduced into the equation, the endogenous problem caused by the independent variable are naturally formulated, which may produce errors of parameter estimation. Therefore, the differential GMM is used to perform first difference on Equation (3.2).

According to the previous researches, there is an obvious endogenous relationship between housing price and land price, and the directions of mutual influence are positive. Therefore, the land releasing price can be defined as endogenous explanatory variable, and the lag phase of $\ln \left(\mathrm{LP}_{\mathrm{it}}\right)$ and $\ln \left(\mathrm{HP}_{\mathrm{it}-1}\right)$ shall be introduced as instrumental variable after the first difference. The 2 - 4 lag terms are used as the instrumental variable in the paper. The differential GMM can reduce the valid sample of models and eliminate the variables that do not change with time. In view of the shortcomings of differential GMM estimation method, the system GMM estimation method is used to deal with the weak instrumental variables and keep the variables that do not change with time [11].

Table 3 shows the results obtained by means of GMM method. Equation (1) is the estimation result by using fixed effect, while Equations (2) and (3) are the lists of estimation results by using differential GMM and system GMM. According to the estimation results of models, due to the excessive application of instrumental variables, system GMM results in the over identification, while differential GMM has a quite high effectiveness due to the less application of instrumental variables as well as the quite low L. (lnhp) coefficient. Therefore, differential GMM estimation is used as the final tracking result in the paper.

\begin{tabular}{|c|c|c|c|}
\hline Test method & Original hypothesis & Statistical magnitude & $P$ value \\
\hline F test & $\begin{array}{l}\text { H0: The intercept terms of } \\
\text { different individuals are the } \\
\text { same (mixed regression } \\
\text { model) }\end{array}$ & 45.75 & 0.0000 \\
\hline Hausman test & $\begin{array}{l}\text { H0: Individual effect has } \\
\text { nothing to do with } \\
\text { regression variable (random } \\
\text { effect regression model) }\end{array}$ & \multicolumn{2}{|c|}{$\begin{array}{c}\text { original: } 52.73 \\
\text { sigma more: } 109.77(0.0000) \\
\text { sigma less: } 78.76(0.0000)\end{array}$} \\
\hline
\end{tabular}

Table 3. F test and test result of Hausman. 
The results of Hansen test and Arellano-Bond residual sequence are prepared at the end of Table 4. The $\mathrm{p}$ value of Hansen test is 0.477 , which indicates that instrumental variable is valid. The residual sequence has first-order correlation but no prominent residual second-order autocorrelation, which proves that the regression results are robust.

According to the estimation results of differential GMM, the elastic coefficient of housing price lag phase on housing price is 0.704 , which means that every $1 \%$ of improvement on previous housing price can drive the increasing of current housing price by $0.704 \%$. The elastic coefficient is far greater than that of other explanatory variables, which indicates that consumers' adaptive expectation on housing price is the major factor that brings about the current rising of housing price. The reality explanation is: the bundling of housing property and public services in China leads to the fact that the public services enjoyed by housing purchasing is far greater than that enjoyed by housing renting. The capitalization effect of public expenditures drives up the housing value, and the housing owners are enjoying the wealth effect caused by the improvement of public services.

Table 4. Robustness test of dynamic panel.

\begin{tabular}{|c|c|c|c|}
\hline & Fixed effect & differential GMM & system GMM \\
\hline & (1) & (2) & (3) \\
\hline & LnHP & LnHP & LnHP \\
\hline L.Lnhp & $\begin{array}{c}0.5694^{* * *} \\
(0.0637)\end{array}$ & $\begin{array}{c}0.7049^{* * *} \\
(0.0491)\end{array}$ & $\begin{array}{c}1.0312^{* * *} \\
(0.0285)\end{array}$ \\
\hline Lnlp & $\begin{array}{l}0.0377^{* *} \\
(0.0155)\end{array}$ & $\begin{array}{c}0.0564^{* * *} \\
(0.0076)\end{array}$ & $\begin{array}{c}0.0489^{* * *} \\
(0.0093)\end{array}$ \\
\hline Lnaee & $\begin{array}{l}0.0685^{\star} \\
(0.0473)\end{array}$ & $\begin{array}{c}0.1049^{* * *} \\
(0.0077)\end{array}$ & $\begin{array}{l}0.0286^{* *} \\
(0.0186)\end{array}$ \\
\hline Lnate & $\begin{array}{c}0.0962^{* * *} \\
(0.0140)\end{array}$ & $\begin{array}{c}0.0458^{* * *} \\
(0.0189)\end{array}$ & $\begin{array}{c}0.0562^{* * *} \\
(0.0054)\end{array}$ \\
\hline Lname & $\begin{array}{l}-0.0540 \\
(0.0416)\end{array}$ & $\begin{array}{c}-0.1166^{* * *} \\
(0.0095)\end{array}$ & $\begin{array}{c}-0.1217^{\star * *} \\
(0.0149)\end{array}$ \\
\hline Lnpcdi & $\begin{array}{c}0.0349 \\
(0.0675)\end{array}$ & $\begin{array}{l}-0.0221 \\
(0.0431)\end{array}$ & $\begin{array}{c}0.0266 \\
(0.0401)\end{array}$ \\
\hline Lnpd & $\begin{array}{c}0.0354 \\
(0.0322)\end{array}$ & $\begin{array}{c}0.0273 \\
(0.0258)\end{array}$ & $\begin{array}{l}-0.0015 \\
(0.0078)\end{array}$ \\
\hline Lnba & $\begin{array}{c}-0.0555^{*} \\
(0.0252)\end{array}$ & $\begin{array}{c}-0.0194^{* *} \\
(0.0080)\end{array}$ & $\begin{array}{l}-0.0060 \\
(0.0066)\end{array}$ \\
\hline Lnlr & $\begin{array}{c}-0.2010^{* * *} \\
(0.0601)\end{array}$ & $\begin{array}{c}-0.2416^{* * *} \\
(0.0175)\end{array}$ & $\begin{array}{c}-0.3216^{* * *} \\
(0.0193)\end{array}$ \\
\hline $\mathrm{R}^{2}$ & 0.9381 & & \\
\hline Sample size & 240 & 210 & 240 \\
\hline Arellano-Bond test for $\mathrm{AR}(1)$ & & 0.008 & 0.001 \\
\hline Arellano-Bond test for $\mathrm{AR}(2)$ & & 0.691 & 0.624 \\
\hline Hansen test & & 0.477 & 0.986 \\
\hline
\end{tabular}


Yet due to the missing of real estate possession tax, the housing owners have obtained the excess earnings that exceed their tax burden level, which goes against the tax revenue principle. To some degree, it has caused the heavy speculative sentiment in Chinese real estate market and formulated a price expectation of

"keep going up", as well as stimulated the housing demand. On the other hand, the lack of flexibility in land supply has reinforced the expectation on rising of housing price.

Meanwhile, when the empirical results of dynamic panel model is compared with that of static panel model, the control variables such as per capita disposable income and urban population density that reflect the relation between supply and demand only have tiny impact on housing price, which reflects that the pricing mechanism of current housing market in China is partial to investment-oriented market and dominated by the expectation of market price.

The capitalization effect of public expenditure maintains significant under the background of investment-oriented market. Among all public expenditures, the elastic coefficient of education expenditure is 0.1049 , while the elastic coefficient of transport expenditure is 0.0458 , which have prominently positive impact on housing price and are consistent with the regression results of static panel.

\section{Conclusions and Policy Suggestions}

Based on the inter-provincial panel data during 2007-2015 in China, the paper performs empirical analysis about the impact of various public expenditures on housing price. Public education expenditure and public transport expenditure have significantly positive influence on housing price. Among the expansions of various fiscal expenditures, public education expenditure is the most effective type to promote the capitalization of commercial housing. The capitalization degree of public expenditure can be viewed as a standard to measure residents' willingness to pay for public goods. Under the condition that land ownership and the right to use are separated in China, the capitalization degree of public expenditure in housing price can fully measure the satisfaction level of public goods supply on residents' preference. According to the empirical results, residents generally have a higher preference for high-quality education resources. The policy of "nearest school" enjoyed by China housing has connected the right to obtain high-quality education resource with ownership of surrounding housing, which has partly intensified the capitalization degree of education expenditure.

The positive impact of public expenditure on housing price shows the increasing growth of demands on high-quality public services. The realistic contradiction is however, the imbalance of regional economic development and the difference in local financial resources, which brings about a wide gap of per capita public expenditure among different regions and the imbalance of public goods supply. The differentiated public expenditure in turn, can strengthen the regional differences of housing price via capitalization. The soaring of housing 
price in the region with more high-quality public services seems to be inevitable.

Based on the assumption that the housing market is an investment-oriented market, consumers' adaptive expectation is introduced and a dynamic panel data model is formulated to perform the robustness test. According to the results, consumer expectation is the critical reason to promote the current rising of housing price, and the housing market has deviated from its consumption attribute but has a much heavier focus on investment attribute. Under the background of investment-oriented market, the rising expectation of housing price comes from the constant public services expenditure, and the housing value is energized by public services, while the capitalization of public services can drive the rising of housing price as well. The capitalization effect of local public expenditure is sound and stable.

In order to promote local government to provide more balanced and more suitable public services for the masses and promote the equalization of public services, the government shall reasonably guide consumers' expectation by virtue of various measures and control the excessive rising of housing price in some provinces and cities. The policy suggestions are as follows:

1) Local government shall adjust the structural and regional proportions of public expenditure so as to cope with residents' preferences. According to the empirical results, the public education expenditure is featured with the highest degree of capitalization, which indicates residents' demand for high-quality education resources at present. Local government shall properly enlarge the proportion of public education expenditure in budget preparation. The central government shall strengthen the payment of special financial transfer to the regions with poor public services and promote the equalization of inter-regional public services. Equalization of public services can partly alleviate the difference of regional housing price caused by the difference of regional public goods supply.

2) Enlarging housing supply through multiple channels, and ameliorating consumers' expectation on housing price rising caused by the imbalance of housing supply and demand. Local government shall properly increase the supply of residential land and lease land, improve the relation between housing supply and demand, and reasonably guide the housing consumption. In order to realize the social equity of housing allocation, local government shall fortify the construction of indemnificatory housing continually and improve the multi-channel housing security system.

3) Strengthening the local tax system and starting to collect property tax as soon as possible. The real estate possession tax based on housing value can significantly enlarge the possession cost of housing as an investment, and partly suppress the current investment demand on real estate as well as the blind price expectation so as to control the inertial rising of housing price. Meanwhile, property tax revenue can provide financial resource for the local government and guarantee the supply of better public services. 
In view of the capitalization effect of public expenditures, the government revenue can be increased by the wealth effect of real estate appreciation, and the revenue growth allows the local government to enlarge public expenditure, thus a positive cycle is formulated. Regional differences on speed-raising of housing price have strengthened the regional gaps among enjoyable public services. Therefore, property tax shall be defined as the central-local shared tax, and the central government shall promote the equalization of public services by means of the shared regional tax and special transfer payments.

4) All local governments shall positively response to the national policy of "coequality of sale and rental", and provide more effective supporting measures. "Coequality of sale and rental" requires that the tenant shall enjoy the same rights of public services as the homeowner do. The policy aims to untie the bundling between housing ownership and public services, and remit the excessive rising of housing price in the scarce public resources. Because of the imbalance between scarce public resources' supply and demand, the inhibiting effect of "Coequality of sale and rental" on housing price is quite limited in the short term. Yet the housing demand shunting caused by coequality of sale and rental can effectively reduce the undulation of real estate in the long run, and become an important measure to formulate a long-term mechanism of real estate regulation.

\section{References}

[1] Tiebout. (1956) A Pure Theory of Local Expenditures. The Journal of Political Economy, 10, 418-422.

[2] Oates Wallace, E. (1969) The Effects of Property Taxes and Local Public Spending on Property Values, An Empirical Study of Tax Capitalization and the Tiebout Hypothesis. Journal of Political Economy, 6, 957-971.

[3] Lang, K. and Tian, L.J. (2004) Property Taxes and Property Values: Evidence from Proposition. Journal of Urban Economics, 1, 439-457.

[4] Liang, R.B. and Tang, Y. (2009) Tiebout Model in the Supply of Local Public Goods-An Empirical Research Based on Chinese City Housing Price. World Economy, 10, 71-83.

[5] Du, X.J., Huang, Z.H. and Wu, C.F. (2009) Study on Interaction among Housing Price, Public Expenditure and Real Estate Taxes-Theoretical Analysis and the Empirical Research Based on Chinese Data. Quantitative \& Technical Economics, 1, 109-119.

[6] Alonso, W. (1964) Location and Land Use. Harvard University Press, Massachusetts.

[7] Bayer, P., Ferreira, F. and McMillan, R. (2007) A Unified Framework for Measuring Preferences for Schools and Neighborhoods. Journal of Political Economy, 4, 588-638.

[8] Li, L. (2013) Impacts of City Public Goods Supply on Housing Price. Huazhong University of Science and Technology, Wuhan.

[9] Zhou, J.K. (2005) Faith, Feedback Effect and Game Equilibrium: A Game Theory Explanation Formed by Speculation Bubble of Real Estate. World Economy, 5, 21-27. 
[10] Sun, W.Z., Wang, D.Y. and Zheng, S.Q. (2015) Local Financial Expenditure, Housing Price and Housing Affordability. Journal of Tsinghua University. Natural Science, 6, 165-177.

[11] Liu, S. and Feng, H.B. (2016) Taxation Structure and Consumption Spillover: Transnational Evidence. China Industrial Economics, 6, 22-38. 